easy. With regard to the Hollerith, the spectacular production of a table of a polynomial function by feeding the machine with blank cards appealed to many at the Cambridge demonstration, while so far as capacity for work is concerned, it may be mentioned that in a recent agricultural statistical investigation, two Cambridge workers produced a million products in six weeks, that is, at the rate of one product a second.

Expensive machines are not readily available to the ordinary scientific worker, and this lends interest to the announcement that Dr. Comrie, formerly superintendent of H.M. Nautical Almanac Office, to whom much of the above mentioned development is due, has set up at 131 Maze Hill, Blackheath, London, S.E.3, a professional "Scientific Computing Service". Dr. Comrie offers his services for (1) scientific calculations generally, and particularly those where mochanical computation and mass production methods may be employed; (2) tablemaking ; (3) purchase and use of calculating machines and mathematical tables; (4) instruction in the art of mechanical computing; (5) press work; and (6) lectures on calculating machines or on computing. He has at his command a variety of machines, includ- ing a "National" and Hollerith equipment. As the former is expensive to buy and the latter to hire, here is a means whereby the scientific worker may get computation jobs done efficiently at reasonable rates.

An interesting announcement from Cambridge relates to the proposed establishment of a computing laboratory in the mathomatical faculty. The immediate intention is to acquire a Bush integrating machine and the Mallock equation solver, but other machines will be added from time to time, and a wide view is being taken of the service that can be rendered to Cambridge by the establishment of such a laboratory. Besides the applied mathematicians; we can envisage statisticians, economists, biologists, psychologists and others being eager to avail themselves of the specialized equipment that will no doubt be available in time, in order to supplement their existing computational resources. The capital cost of the proposed installation is of the order of $£ 10,000$, and it is anticipated that an annual charge of $£ 1,000$ per annum will fall to be met by the University, to include maintenance and replacement of machines, and salaries. The scheme has been approved, and the laboratory should be in existence by the opening of the academic year in 1938 .

\title{
Hybrid Vigour in Plants
}

$I^{N}$ CREASED vigour over either parent of the product of the cross between two inbred lines has been frequently reported in plant breeding and, through vegetative propagation, ciforts have been made, especially with trees, to make practical use of the phenomenon. It is usually explained, in Mendelian terminology, as the result of association of several genes for size which had been isolated in either parent, and subsequent loss of vigour in succeeding generations is attributed to segregation. There has been little analysis, however, of the factors contributing to the heterosis or hybrid vigour during the development of the hybrid, so that considerable interest is attached to a recent series of papers by Dr. Eric Ashby, which havo brought to light some most unexpected features of this process in specific cases.

In certain strains of maize ${ }^{1}$ and in two cases with tomato strains ${ }^{2}$ where the hybrid showed greater weight and dry weight, greater height, more leaves and larger leaf area than either parent, analysis of these differences showed no appreciable difference between hybrid and parent in relative rates of growth or of dry weight increase, of rates of production of leaves and new leaf area or of photosynthetic efficiency. Cell size in hybrid and parent also seemed approximately the same, but the embryo of the resting seed seemed larger in all cases.

The only possible conclusion from these results would seem to be that the organization of the growing shoot of the hybrid is upon a larger scale. Embryo and shoot apex form cells more rapidly, but this does not result in a quicker release of leaf primordia from the shoot apex because the whole plan of shoot organization, though still that characteristic of the species, is built upon a larger scale. More cells must accumulate at the apex before the new leaf primordium must separate. Naturally, therefore, when it arises, this primordium is planned on a larger scale from the outset, presumably its procambial and vascular strands are commensurately larger and it grows into a larger leaf, though individual cells, in their metabolic and photosynthetic efficiency, correspond with those of the parent forms.

Dr. Ashby speaks of larger primordia in the seed, but the term is usually applied to leaf primordia, and in the embryo of the tomato, apart from cotyledons, leaf primordia will scarcely be manifest yet. It would seem that the comparison is rather upon the scale of organization of the meristematic aggregate in the hybrid shoot; planned on a more generous scale, it yet maintains the rate of leaf development of the parent, so that its growth must mean a larger number of meristematic cells maintained in full activity at any moment, therefore more cell divisions and the growth organization of the species main. tained at its usual tempo but on a larger scale.

Dr. Ashby's studies are therefore full of significance in relation to the problem of shoot organization in the higher plant, as well as in connexion with the genetic explanation of hybrid vigour. Dr. Ashby points out that his results are not in accordance with the usual interpretation given to the linkage of genes in the $F_{1}$ generation, but there is as yet so little information as to the way in which the gene is geared into the machinery of development that it is early to say whether the conventional explanation in terms of genes can be applied to the machinery now revealed as operating in the development of the hybrid.

${ }^{1}$ Ann. Bot., 44 (1930) and 46 (1932).

${ }^{2}$ Ann. Bot., X.S., 1, 11-12 (1937). 